\title{
DISCOVERING AND PRESERVING THE MILITARY LANDSCAPE. ICT FOR THE GERMAN BUNKERS OF THE GALLA PLACIDIA LINE.
}

\author{
C. Mariotti *, A. Ugolini, A. Zampini
}

\begin{abstract}
Alma Mater Studiorum, University of Bologna, Department of Architecture, Bologna, Italy chiara.mariotti7@unibo.it, a.ugolini@unibo.it, alessia.zampini2@unibo.it
\end{abstract}

KEY WORDS: German bunkers, military landscape, preservation, communication, ICT, heritage communities, Beacon, outdoor

\begin{abstract}
:
The research here presented reflects on the potentials of enhancement, given by new Information and Communication technologies, in the field of Culture Heritage. It describes an interpretation and communication project for a military landscape built during World War II by the German troops. Known as Galla Placidia Line, it was a network of heterogeneous fortifications like bunkers, defensive emplacements and dragon's teeth erected between Pesaro and Ravenna along the coasts of Emilia Romagna.

The project bases its roots on the development of a rigorous census, thought as an implementation of the online open-source catalogue established by the entrusted Institutions. The direct and indirect surveys required in order to describe these structures according to a specific set of characteristics will increase their knowledge and relative awareness and it will constitute the starting point for developing new narrative contents. The communication and interpretation of these data will go through the use of locating intelligences - an integrated GPS and Beacon system - involved into a new application. A tool witch is meant to help and empower local communities and institutions not only in making this heritage known but also in its conservation policies.
\end{abstract}

\section{INTRODUCTION}

This paper explores the centrality of Information and Communication Technologies (ICT)-based services for the knowledge, interpretation, dissemination and enhancement of the German bunkers of the Galla Placidia Line.

Built along the Adriatic coast, this network of forgotten and underused military architectures is an exemplary case for investigating the potential of intelligent digital technologies in the field of communication for preservation - open-source digital archives, interactive and geo-referenced maps, virtual tourism, virtual installations, soundscapes and last but not least civic engagement for managing Cultural Heritage - .

An integrated technological system whose development seems to ensure a new narrative for built heritage through which to strengthen the sense of places and the individual and collective memory, to discover and interpret this military landscape, but also to increase its capacity of 'resilience' management from a social, economic, environmental and cultural point of view.

The following is a description of the work done so far to meet this challenge: a project still in its early stages capable of integrating skills and expertise related to restoration and geomatics for the future of a legacy that deserves a 'second life', both virtual and real. [CM; AU; AZ]

\section{GERMAN BUNKERS OF THE GALLA PLACIDIA LINE}

\subsection{History of the defensive system}

September $8^{\text {th }}, 1943$. This date, the day when the Armistice between Italy and the Allied forces was disclosed, marked a turning point for the outcome of the Second World War and above all for what concerned the disastrous consequences registered by Italy in terms of human loss and destruction of cities. The former allied German troops suddenly turned into an occupying enemy whose strategy was to fight for each single inch of lands in their control.

Because of this warfare, when the German forces realised that the Allied could plan a landing via Adriatic Sea, north to what was considered the last fortified line before entering the heart of the Reich, as to say the Gothic Line, they decided to build up a coastal active defensive system. The given codename was Galla Placidia Line (Montemaggi, 2008) (Figure 1).

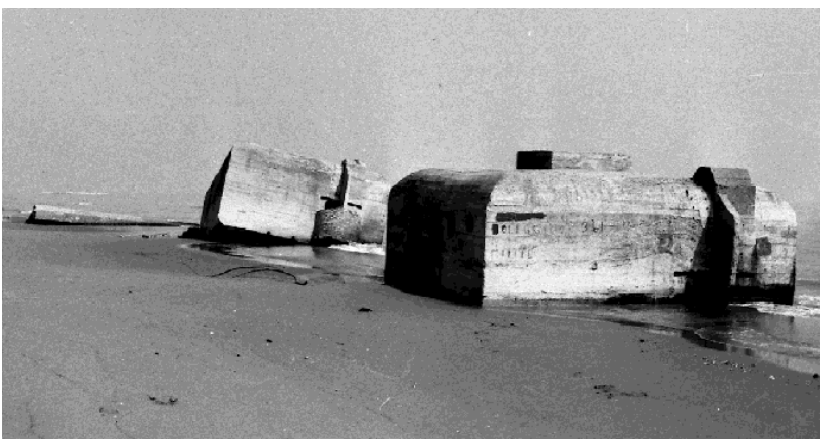

Figure 1. Lido di Savio (RA), Abandoned bunkers along the beach. (C) Giordani, 1971.

This fortified line run for about $130 \mathrm{~km}$, from the San Bartolo Mountain near Pesaro till the seashores of Ravenna. This line was made of more than 2.800 reinforced concrete bunkers and other anti-shipment elements known as dragon's teeth: a monumental edification that increased the strength of the borders of the so-called "Festung Europa".

The Todt Organization had a key role in this entrenchment process as it was entrusted with the arduous tasks of coding all the types individually developed by the Wehrmacht Corps, standardizing their characteristic. The aim was quicken the realization, gaining a maxim adaptability to different contexts

\footnotetext{
* Corresponding author
} 
and situations. The result was a series of handbooks, known as "Typenheft", literally 'standardized design', where about 700 structures were collected and meticulously depicted thanks to detailed measured drawings and technical captions (Figure 2). Great attention was paid to the concrete composition as it had to be exposed to marine environment, to the stages necessary to optimize the construction, to the internal furniture, but also to the plant equipments whose housing were accurately designed and prepared during the casting phase. Nothing had to be left unplanned or unsolved in order to maximize the defensive potential.

The first bunker typology developed was called "Regelbau" followed by a three-numbered code that identified the various conformations; later on a more compact kind was defined in order to speed up even faster and simplify the construction. Known as "Bauform" this second kind of bunkers was in turn divided into "Ringständ" or "Tobruk" and "Pantherturm, whilst the term "Panzernest" identified a last completely precast series (Kauffmann et al., 2003; Boglione, 2012, Mariotti et al., 2018).

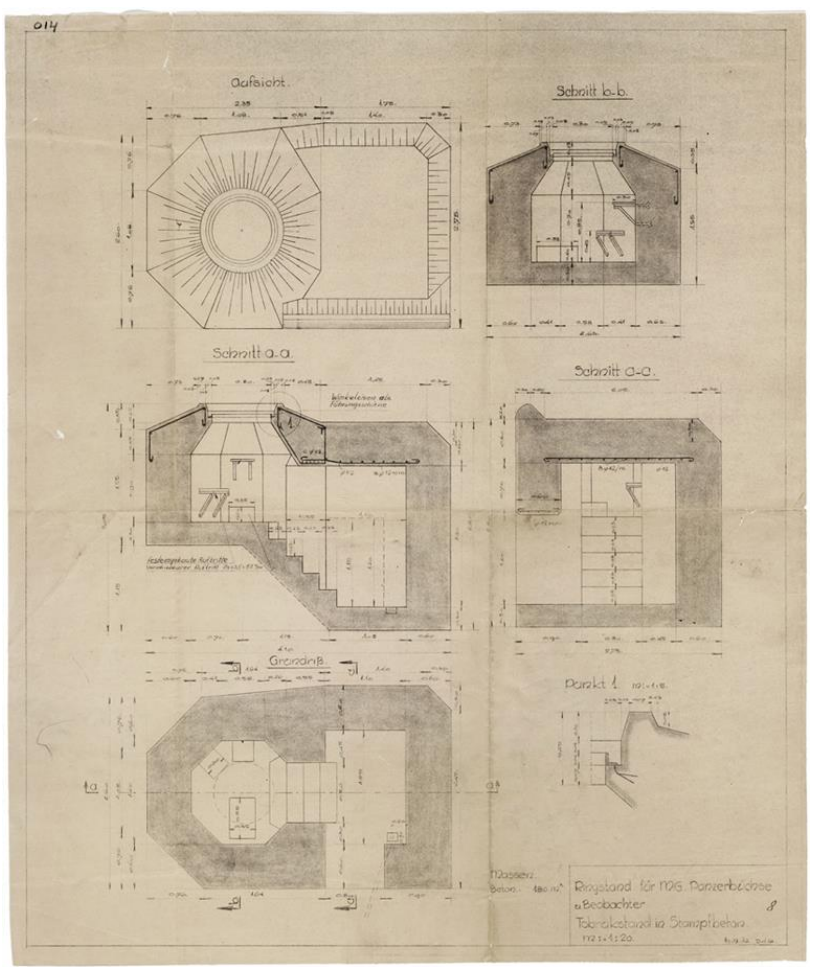

Figure 2. Tobruk, Plans and sections. National Archives of the Netherlands, Le-Hague, Bunkerarchief, 2.13.167, inv. nr. 1038, public domain.

In any case, despite this huge mobilization and organization, the war events revealed a different Allied plan: thanks to the Operation Olive the Gothic Line was breached by land and the Romagna coasts with their fortifications entitled to Roman Empress were spared from a sea attack, which revealed to be a red herring. The core of the battle had moved to the Normandy coasts.

The end of the war meant therefore a decision about the fate of these 'silent witnesses' of a landing that never took place. As the Peace treatise ordered their demolition, they were largely destroyed, but they had been built in order to resist the war and their complete dismantle turned out to be very complex. Some of them where consequently buried or intentionally covered by sand, a few were even reused as storages and warehouses. They were rejected ruins of a war to forget, subjected to a damnatio memoriae that led to their oblivion.

The lights on the German fortifications system were turned on again in the 70s, when Paul Vilirio, for the fist time, wondered about what he defined the "Bunker archaeology" (Vilirio, 1975), but only a recent interest of a local community on this specific area projected the challenge of it preservation toward the present day. Aware that to avoid facing the past and to escape from processing its signs could be a thread for the future (Bassanelli et al., 2013), a new reflection has to be carried out. How the restoration process and the new ICT enlarging its potentialities could help communicating this controversial and uncomfortable heritage? Which are the main issues to deal with? [AZ]

\subsection{Complexity, criticality and potential}

The remains of the German bunker system are today just a fragmented set of architectures, which have mostly no purpose and they are absorbed in the contemporary urban structure without any conservation action.

The main issue is, therefore, that it is almost impossible to recognize and figure out the scale of this complex defensive system, built as a network of connected fortifications and strongly integrated into the coastal landscape.

A further problem is that of bunkers on an architectural scale. The remaining structures have undergone a gradual process of metamorphosis, sometimes spontaneous and sometimes intentional, that has compromised or forever altered their material consistency, making it difficult to read them even at close distance. Abandoned bunkers are overrun by vegetation, while those that have been reused are so transformed that they are sometimes unrecognizable - brought back to the surface, covered with new materials, equipped with doors, windows, stairs and roofing - (Figure 3 ).

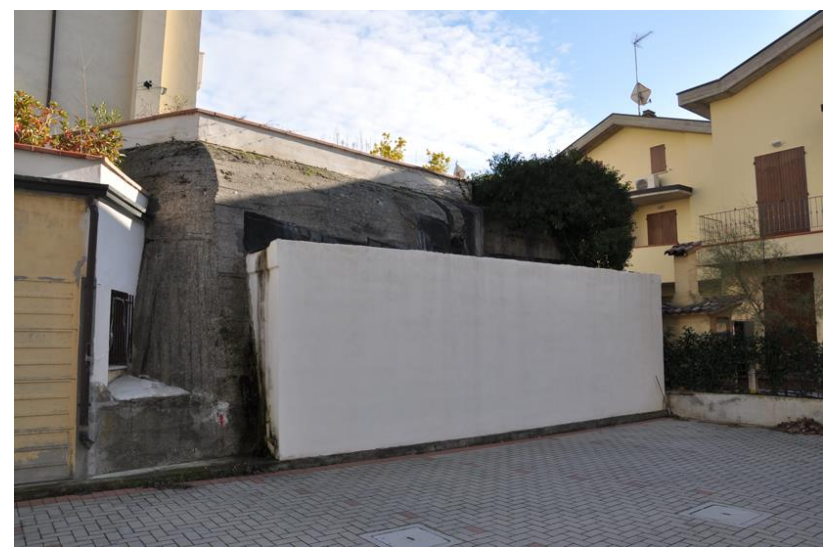

Figure 3. Lido di Savio (RA), Example of a bunker embedded in contemporary buildings. (c) Zampini, 2018.

The lack of a specific protection regulation is one of the main causes behind this: bunkers, like all items of particular historical interest, are in fact protected by the Code of the Cultural and Landscape Heritage (2004, art. 12) provided that they are owned by public bodies and that they are at least seventy years old. Nevertheless, the fact that most of these buildings do not meet the above-mentioned legal requirements - they are privately owned and all have only recently turned seventy proves that the lack of ad hoc regulation has fostered a carefree attitude towards this historical inheritance. In 2003, an attempt to extend the Italian law regarding the Safeguard of the World War I inheritance (2001) to the vestiges of World War II failed and even today the situation has not changed yet. 
The first conservation actions on these military architectures date back to the 70 s and they have almost always relied on volunteers. In the Romagna area, in particular, the no-profit organisation Comitato Ricerche Belliche $360^{\circ}\left(\mathrm{CRB} 360^{\circ}\right)$ still coordinates today a series of operations including reconnaissance of bunkers, removal of shrubs and weeds and, in some cases, excavation, camouflage painting of surfaces and fitting of interior rooms. Works carried out in 2014 on the bunker, model "Vf59a", located in Amerigo Vespucci street in Cesenatico, serve as an example to clarify the activity of the CRB360 ${ }^{\circ}$ (Figure 4).
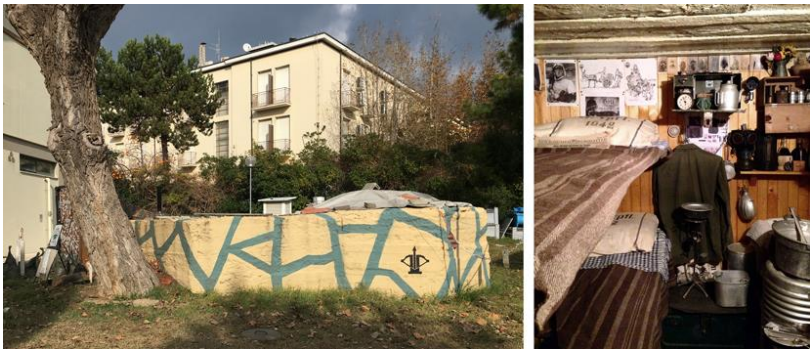

Figure 4. Cesenatico (FC), Examples of CRB360 ${ }^{\circ}$ activities. (C) Mariotti, 2018

In the cultural framework outlined above, ICT seem to be the most effective tool for overcoming highlighted problems and to promote the still untapped potential of this built heritage. Their development and implementation can set out new ways of accessing heritage, activate processes of re-appropriation of places, allow for a systemic vision of this historical military landscape, support the collection and systematization of data, as well as involve the community in conservation and maintenance activities. It could create a new virtual narrative for preservation as "good story-telling, using all opportunities offered by digital technologies, is the key to conveying the history of the place and enhancing its heritage value" (Architects' Council of Europe et a., 2018). [CM]

\section{THE PROJECT}

The project presented will be oriented towards the knowledge of this forgotten heritage, the understanding of its stories and the participation of local communities in the processes of its preservation. A protection based on an articulated program where the identification of the artefacts, their recognition on territory and their conservation represent a unitary path. The use of ICT in the transmission, reception and processing of data and information is therefore necessary in several respects: from the collection of the data to its dissemination (also for popular purposes) up to its management, permeating the whole process. Let's not forget that if the safeguard is intrinsic, the enhancement will be extrinsic, because it widens and qualifies the communicative potential of a cultural asset. This enhancement is addressed to what may arise from a cultural entity, to the network of values and relationships that strengthen its bond with the communities. The final aim of the project will be to intensify the engagement of local communities in the process of planned conservation also with the help of userfriendly management systems. [AU]

\subsection{Cataloguing}

The catalogue is the indispensable tool for every form of protection. No institution can ever guarantee a reliable conservation programme without an up-to-date list of cultural assets entrusted to it or even potentially capable of being so.
This leads to the emergence of identification problems, especially related to the fact that Cultural Heritage is a complex phenomenon in continuous transformation: today we identify as bearer of values and worth of protection what was not the case yesterday. That is what happened to the case of the German fortifications on the Romagna coast. A still incomplete knowledge, the dispersion on the territory, the different ownership and their consequent different legal regime, makes it indispensable to put a unitary cataloguing at the base of the project. The functions of a catalogue, indeed, are not limited to the scan and census of the area, but if they are associated with processes of interpretation and dissemination of the collected data - which we will try to demonstrate here - they may ensure preventive actions of monitoring and promote maintenance and conservation. The desire to consolidate collaborations with other institutions actively present on the territory and the need to avoid the knowledge fragmentation of this heritage into countless containers has led to the opening of a dialogue with the main institutions filing the region, namely the Institute of Artistic, Cultural and Natural Heritage of Emilia Romagna $(\mathrm{IBACN})^{1}$. Although they do not share the same ontologies, thanks to a series of protocols of understanding, the IBACN periodically pours its efforts in the national catalogue developed by the Central Institute for Cataloguing and Documentation (ICCD), the reference body for the cataloguing of the Italian Cultural Heritage. The IBACN also manages the Cultural Heritage Catalogue of the administrative area under its control (PatER). It is a portal that allows an overview of the historical and cultural memory of Emilia-Romagna: the cultural sites are here geo-referenced and can be explored together with works of art, archaeological finds, demoethnoanthropological, historical and scientific evidences that are contained therein. The inventory is constantly being expanded in terms of type and quantity of the cultural assets on file. All the contents proposed are 'shareable' with the main social networks: Facebook, Twitter, Instagram, Google+, Pinterest. The portal applies responsive strategies in order to ensure an optimal user experience through mobile devices, such as smartphones and tablets. The IBACN, moreover, had already been involved since 2007 in a complex project entitled "Gothic Line" which included the detailed record of testimonies and artefacts from this specific district also relating to the Second World War. The aim was to build a 'networked territorial system': a sort of integrated historical museum organised at a regional level, with the functions of a container for memory, cultural identity and landscape. In its feasibility the committed administrations at all levels, cultural bodies and institutions, associations and citizens were fully involved. The project regarding the fortifications for the active and passive German defence of the Second World War along the Galla Placidia Line, will therefore be fully inserted in a program with a strong systemic value already existing, which will enrich the whole contents. For the cataloguing project, the tabs Type A - Architecture provided by the institution has been chosen. These must be compiled according to the vocabulary developed by the ICCD in order to achieve a degree of depth at least pre-catalographic if not catalographic. The assignment will starts with the collection of archival documentation relating to manuals (building regulations and bunker types as contained in the Typenheft),

\footnotetext{
${ }^{1}$ The IBC was founded in 1974 as an instrument of regional planning and a consulting body for local authorities in the field of Cultural Heritage, it promotes and carries out cognitive and operational activities, investigation and research, for the enhancement and restoration of the historical and artistic heritage of the Emilia Romagna region.
} 
documents on their disposal and/or demolition at the end of the war (Todt and local historical archives), archive images taken during the war (Todt and Bundesarchiv Archive) or during the liberation (National Archives in Washington, National Archives of the Netherlands, New Zealand Libraries etc.). The buildings, still preserved, will be geo-referenced (Figure 5) and their properties will be identified; the types and characteristics will be described (traces of camouflage, decorations made by the troops), the remaining plants will be documented and the accessibility of the artefact will be verified. Finally, the project will describe the state of conservation with photos and diagrams; also the date of the inspection will be recorded on the monitoring card of the single object.

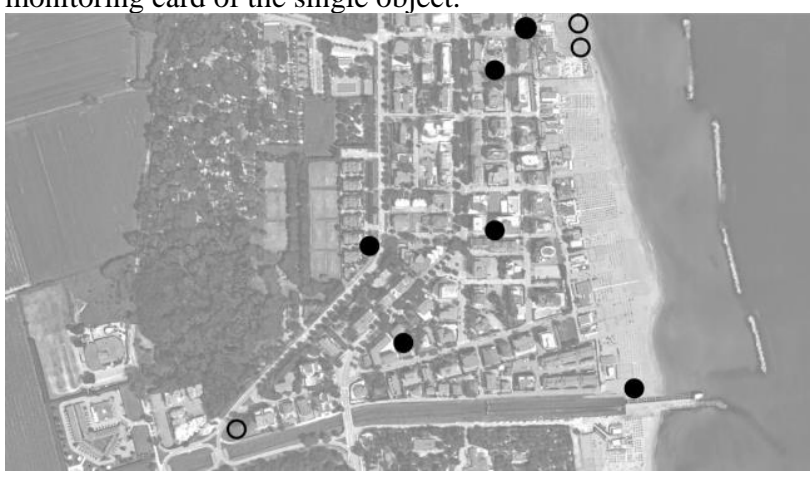

Figure 5. Lido di Savio (RA), Map of the existing and destroyed bunkers. (C) Mariotti, Zampini, 2018.

The analysis and recording process will be carried out by trained staff coming from the university (curricular internships), with the support of voluntary associations already active on the territory and local multi-stakeholders.

The cataloguing activity will become a basic cognitive tool, always open, useful for scientific research and comparative study but also for the monitoring of the asset aimed at its planned conservation. [AU]

\subsection{Developing an application}

3.2.1 Precondition and the state of the art: Once the cataloguing activity will be completed, the project would challenge the dissemination of the recorded information, aiming as already stated, at increasing the knowledge and the collective awareness about this controversial heritage. The core idea is that this attentiveness could be encouraged and fed through the opportunity of interpreting each defensive building as a part of a past and present landscape, which is complex and rich in meanings and stories. Thus, a new kind of communication should be experimented, an interactive approach granting the access to both archival documents and further media contents, giving the opportunity to match the experience with the different visitors' expectations and to target diverse audience groups.

Since the preliminary phases, new ICT revealed their potentialities because of their effectiveness in engaging the tourists and communities' attention; especially considering that themes related to World War II could be highly attractive to a school-age audience, which is largely accustomed to high-tech devices. Moreover, years of experimentations are leading them becoming the favourite choice for museums and cultural institution in order to foster the contents accessibility and the general fruition quality (Network, 2017; Fernandes Vaz, 2018). Despite the ability of promoting the visitors' return, the digital interface involves a risk that should be warded off, that is the switch between content and container occurring when the technological devices become more interesting than the information they convey. Therefore taking advantage of the "variability" of digital media (Manovich, 2011) while preventing tourists from sitting still behind a screen was a predominant ambition.

For all these reasons it has been selected the development of a responsive application that can be remotely used, but which is also enriched with exclusive contents (not merely visual) accessible only in situ. The purpose is to encourage the physical visits of these places and, at the same time, to help local stakeholders in promoting and enhancing this Cultural Heritage with a low-cost, user-friendly and easy-to-manage tool.

Finally, due to the wide extension of the Line, at first the application will be tested in the north part of the system, from Rimini till the Ravenna seashore, while future developments will be evaluate in the future. [AZ]

3.2.2 Architecture of contents: After the download of the application a minimum data set will be immediately available to users, information that are considered essential in order to plan a customized visit or to have a general overview.

The home page will offer a brief description of the project and it will be enriched by a slideshow whose rotating pictures will direct to every single section.

Among these sections, the first one will provide an historical and cultural introduction to the whole German defensive system focusing on the history and development of the Galla Placidia Line.

The first parts here described are meant as single pages with defined contents, on the contrary the core of the application dedicated to single bunkers will be built up in a implementable way. This section will be split into two different possible displays, corresponding to the twofold kind of inquiry a visitor could deal with. On one side, the exact GPS coordinates acquired during the census (Figure 5) will be pointed out and visualized on a map which could be useful for the remote experience, when for example planning the visit in order to have an overall view of each zone, but also to guide the transfers inside the area. On the other side a grid view will enlist them as associated to an identifying photo, aiming at facilitating a search by object. From both the screens, it will be possible to click on a specific bunker landing on its dedicated page: a sort of flash card resuming the main outcomes of the cataloguing activity. Further information like detailed descriptions, curiosity and media contents (video, audio, augmented reality, ...) will rest a prerogative for physical visitors (see paragraph 3.2.3).

Another fundamental part of the application will be the join the search area; here, anyone who will identify emergency situation of decay and degradation or even not detected structures could send a notification, sharing its position and uploading a meaningful photograph. A team of specialists belonging both to the university and the responsible institutions joined by the local experts will consequently start the procedure for validating the alert. A fundamental opportunity to improve the census and the monitoring activities. Moreover, as already stated, making visitors feeling directly involved in this sort of 'treasure hunt' is a very important ambition for increasing awareness and knowledge.

Exactly for this reason, also a join the community section will be foreseen. News, curiosities, and also the links to the active Facebook pages administrated by the group of volunteer will be provided here. The aim is to create highly engaged readers that could join not only the online debate. The platform, indeed, will be used for launching guided tours or calls for volunteers whose potentialities will be carefully explained in the paragraphs 4.1 . 
Last but not least a page will provide all the contacts of the institutions and associations in charge of the whole process of conservation (preservation strategies, management and enhancement). [CM; AZ]

\subsubsection{Using location intelligence for boosting the remote} experience: In addition to the desktop-based resources, the app will propose an immersive in situ experience, thanks to what has been defined "location intelligence", namely the digital strategy of mapping the positioning and its association with data (Fernandes Vaz, 2018).

The challenge is to guide tourists in an area that runs for miles and at the same time to help them in recognizing bunkers in a more restricted context as they are not always easily detectable. This is due to the fact that they have been camouflaged, transformed, partially buried, damaged or also frequently covered by the shrubby vegetation of the pinewoods that characterize these coasts. For this reason an integrated use of geofencing and proximity technologies has revealed to be the most suitable choice.

Thanks to the GPS coordinates of some specific peripheral bunkers, it would possible to establish a geofence corresponding to the selected part of the Galla Pladicia Line, alerting whoever enters the zone of the historical and cultural importance of this area. In this way also who do not know the application or the project could have the chance to discover it. In fact this technology is able to sends push notification to all the mobile devices with a GPS systems activated.

Once discovered the project and downloaded the app, the proximity sensors will come into play. For what concern this technology, the choice fell on beacons, released for the first time by Apple in 2013 and now suitable also for Android. Since their launch, they are progressively turning to be a revolutionary technology also in the Cultural Heritage field and even if the scientific literature and the current applications had focused on their indoor use (Fernandes Vaz, 2018; Kuflis et al., 2012), also their outdoor potentialities revealed to be very interesting. Applications like "Exploracity" - developed for Genoa -; "Canali di Bologna" - which describe the named city watercourses -; "Streetmuseum" - meant for transforming the whole capital into an open-air museum -; but also the "Omaha beach" which is dedicated to World War II are examples of extremely impactful and engaging tools for the description of cities or wide areas and they are all beacon-based.

The system is formed by very small low-frequency transmitters leveraging Bluetooth Low Energy (BLE) which are able to recognize the presence of portable devices supplied by specific beacon detectors usually acquired when downloading the app. Main qualities of the systems are the extreme accuracy as they can detect positions in a very close range (even few centimetres) and the very long life of the batteries that could last even for 5 years without maintenance (Apple, 2014). Once established the dialogue, transmitters have the possibility to send additional computer data and multimedia contents, overwhelming the QR codes and the NFC technologies strictly based on an awkward action of scan or tap (Liuc, 2015) and definitely transforming the engaging action from a pull to a push approach that best answer the reluctance or indolence of some tourists.

In addition to that, it is important to underline that there are general application able to locate any kind of beacon regardless of its scope, and this represent a further opportunity to learn about the project.

Each bunker will be therefore provided with this kind of transmitter, which is very small and alimented by its own battery, and when someone will be near, the app will alert with a message conveying additional contents.
Among these extras the Augmented reality will be experimented, especially for what concern the overlapping of historical photos on the framing of the mobile devices integrated cameras (Figure 6); but it will be possible to see also pictures of the interiors, to hear readings of literature pieces or detailed description pinpointing the attention toward some important details. This will give a further support to the already active real bunker tours, but also leave the opportunity to visit them whenever and independently.

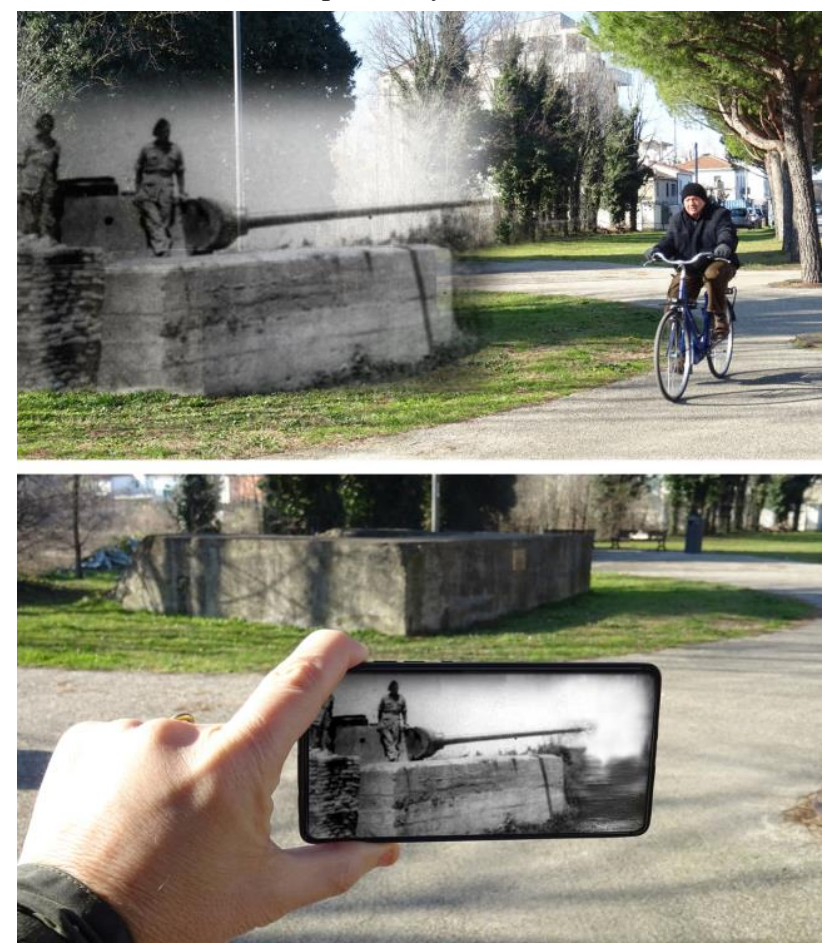

Figure 6. Augmented reality simulation. (c) Bostrenghi, 2019

Features that perfectly meet the need to communicate a spread landscape system where a physical visitor centre could be considered completely out of scale, not only for economic reasons. Here ICT could really represent a key instrument and framework for the management of this peculiar heritage. [AZ]

\section{A BROADER PERSPECTIVE}

\subsection{Community engagement through ICT-based service}

The ICT-based service described above aims at meeting knowledge, communication and dissemination needs, as well as to support inclusion, active participation and controlled direct actions on defensive buildings. Despite its virtual nature, the application, conceived as a tool to discover and preserve, will be a digital integrated system that will produce very concrete results in the real world.

Firstly, this technological device will promote on-site visits. By limiting multimedia contents available remotely, it will encourage users to go on site, promoting real-life experiences, because it starts from the idea that space and story, although intertwined, are part of two very different parallel worlds: if the former is the reality in which we live, the latter is just a screening of this, which is always distorted with respect to direct experience (Corbellini, 2016). When looking at the architectures that transformed the Italian coastal landscape during the Second War World, citizens and tourists will have the opportunity to establish a new or renewed relation with those places and their collective memory, to increase their sense 
of belonging and citizenship - even if by contrast - as well as to play an active role in preservation strategies.

Secondly, the app will foster democratic participation of local communities in long-term conservation and maintenance. The sections joint the search and joint the community are designed to increase interest, awareness and public responsibility for the bunkers and this long neglected military landscape. Experts such as historians, archaeologists, architects and restoration workers are usually mainly responsible for identifying and mapping heritage and developing appropriate solutions for its conservation, but the contribution of citizens can be equally crucial.

Such a vision reflects the importance of a people-centred approach for the protection of the built environment, as proven by the most recent and international documents, conventions and charters on Cultural Heritage. A "new paradigm for socially - and culturally - sustainable heritage action" (Fairclough et al., 2014) is defined by the Faro Convention that recognises "individual and collective responsibility towards cultural heritage" and fosters the concept of a "heritage community" to be actively involved in the whole safeguard processes especially thanks to the use of digital technologies (Council of Europe, 2005). This assumption, which is true for architecture, is then extended to "the complex layering of urban areas" under the Recommendation on the Historic Urban Landscape that equally emphasizes the importance of increasing "civic engagement" by integrating the ICT into urban governance (UNESCO, 2011), according to a guidance for the conservation and management that is progressively going to strength the relationship between society and landscape, people and places (ICOMOS, 2013). This is also the perspective of the UNESCO Management Plans based on an "inclusive approach" to heritage perceived "as the shared property of communities and a factor in ensuring the sustainability of those communities" (UNESCO et al., 2013).

In the case of German bunkers, the idea is to encourage, with the support of this smart digital tool, bottom-up initiatives enabling users not only to passively access the multimedia data conveyed online, but also to actively contribute to their creation by taking a real proactive role.

Users will be able to perform the following activities through the app:

- sign up for physical bunker tours, or on-site guided visits in which they will enter buildings usually visible only from the outside, thus becoming intimately connected with the spatial dimension of these fortifications;

- sign up for volunteers' recruitment to be involved both in the promotion of knowledge of remaining structures for example by working as tour guides in the bunker tours themselves, and in basic maintenance operations to be carried out around military buildings such as grass cutting or waste cleaning. As for maintenance, through the app, users will be also able to update monthly actions - checking those that are done or still to be done - that will make up the maintenance agenda of every single bunker whose activities will be listed in advance by experts in the field of conservation;

- support fundraising and crowd-funding campaigns by paying a small contribution for the most urgent conservation and restoration interventions as well as for the promotion of enhancement initiatives;

- enrol in educational training courses aimed at training citizens to carry out small maintenance activities that, while not requiring specific skills and competences, will increase their knowledge, awareness and responsibility toward bunkers.
Users will also have the opportunity to send one or more notifications to the app, which will be useful to fill gaps in knowledge and to direct the strategies of conservation of this military landscape. A team of experts from Universities or scientific institutions will later validate all notifications. In particular, users will be able to:

- report the discovery of bunkers not yet registered and catalogued by sharing their position and uploading meaningful information such as photographs or notes that will help experts in the validation process;

- signal degradation that will seem to put at risk the conservation of defensive structures such as cracks, weeds, infiltrations, water stagnations and so on. Here, as well, users will identify the bunker affected and upload data for the scientific validation. Experts will later grade all accepted alerts based on the risk and urgency, moving them from the digital application into a special reporting system, intended as a database on the state of conservation of each fortification. For the local administration and the team of experts, this report will become an important instrument for designing preventive and planned conservation programs. It will not be available on the app, but it will also include maintenance operations by volunteers, which will become an integral part of the above-mentioned monthly maintenance agenda of bunker;

- point out imminent danger situations to avoid serious impacts on bunkers, such as the start of works involving roads or buildings in their immediate surroundings, which will seem to ignore their presence in the area.

Community engagement through this ICT-based service also will help support and rationalize the current range of activities carried out by voluntary associations already existing in the region. Such an interactive device will probably find fertile ground especially in Romagna, along the coasts of Cesenatico, Cervia and Lido di Savio where, for several years now, a group of local citizens - history lovers, attentive observers, sometimes owners of defensive buildings - has implemented such activities through the above-mentioned Comitato Ricerche Belliche $360^{\circ}$, which promotes the survival of this controversial inheritance (Figure 7).
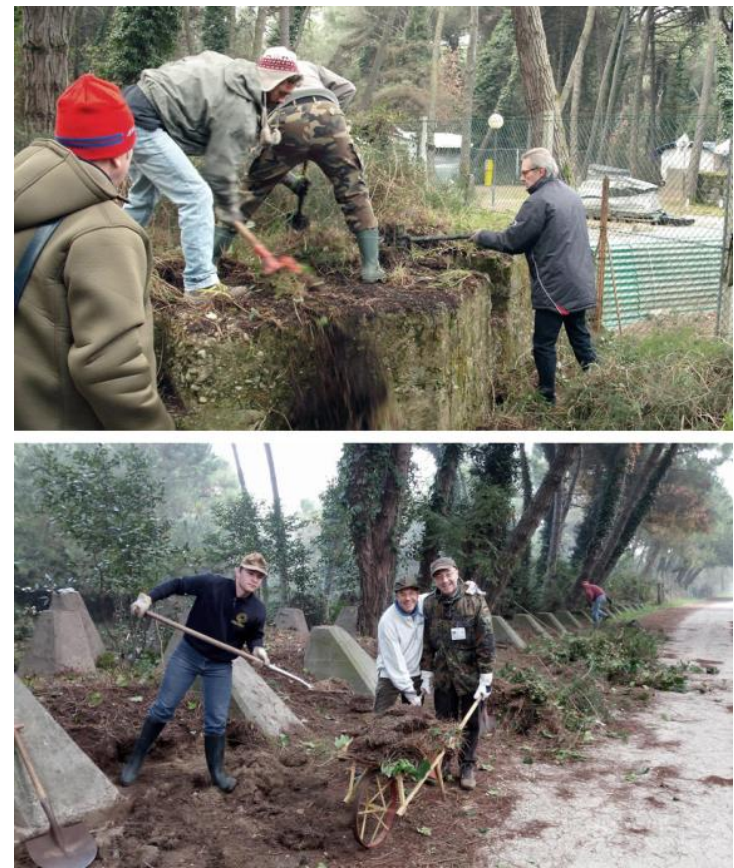

Figure 7. Local community at work. (C) CRB360 ${ }^{\circ}, 2014$ 
The enthusiasm of volunteers will thus be fuelled by the engagement of new recruits, hopefully young ones, and they will also be supervised, in order to avoid maintenance actions that are not always appropriate, like the repainting of the bunkers' surfaces, just to name one of the most critical ones so far. Where, on the other hand, no voluntary association is active yet, this digital tool will be the backbone for promoting and implementing new processes of inclusion in conservation strategies.

This technological system will become an updatable data repository, a dynamic platform for exchange and interaction, an extremely concrete resource for the long-term preservation of the historical military landscape of German bunkers of the Galla Placidia Line. Building communities that actively engage in heritage conservation through the development of ICT-based services seems to be the right way to bring about guarantee cultural, conservative, economic, social and environmental results. $[\mathrm{CM}]$

\subsection{The kicking impact on etourism}

Looking forward to the future and in a broader perspective, it important to realize that Tourism has a very striking impact on the contemporary society, so strong to let physicists and sociologists considering this, the "age of tourism" (D'Eramo, 2017).

Observing this project according to this point of view it is possible to observe that Emilia Romagna region has a very strong touristic vocation; with about 60 millions registered visitors in 2018 (Osservatorio, 2019), it is one of the top three regions chosen by Italian and foreign tourists as a holiday destination. This numbers corroborates the great attractiveness of the coastal area where bunkers are located, the so-called Riviera Romagnola representing a favourite precondition for the good outcomes of the projects.

A recent survey (B.E.M., 2018) however, did not confirm this successful result for what concern etourism, as to say regarding the digitalisation of all the process and value chains in the tourism, travel, hospitality and catering industries that enable organisations to maximise their efficiency and effectiveness (Buhalis, 2003). The region only achieves the sixth place in this ranking. The path carried out could be therefore considered also a possible instrument in order to increase and improve this kind of touristic proposal.

Moreover it is interesting to notice how this systems could be expanded, involving the possibility to involve the whole coastal line but also the Gothic Line places, in order to retain visitors in and incentive tourism also toward the internal areas. [CM; AZ]

\section{CONCLUSION}

The project described is part of an experimental research applied to the conservation process for Cultural Heritage, seeking to combine crucial challenges for its future.

The activity planned aims at exploring, with the support of a technological system, the balanced application of technical solutions able to satisfy multi-level needs in a transversal way. At a time of profound change, technological innovation becomes a powerful means for implementing strategies that offer interesting real effects in the field of protection, enhancement and management of the historic built environment. In order to make the German bunkers of the Galla Placidia Line more handily comprehensible, and their knowledge transferable, a huge applied research has been opened regarding an affordable and accurate acquisition of data, interoperability and usability of content, potentials of communication, community engagement, long-term preservation and long-term accessibility. In this way, the possibilities to obtain results that a few years ago seem to be achievable only through a complex set of restoration works and policies are here endlessly extended. The ICT-base service designed for the military landscape along the Adriatic coast, while not acting directly and concretely on the materiality of the pre-existence, will build a network of plural and attentive visions, a sort of cultural framework that will increase its knowledge and convey actions. These, in turn, will produce multiple benefits on this urging people - experts, local communities, tourists - to interpret it, share it, respect it and actively work for its permanence in transformation. [CM; AU; AZ]

\section{REFERENCES}

Architects' Council of Europe, EFFORT, ERIH, Europa Nostra and FRH, 2018. Leeuwarden Declaration. Adaptive re-use of the built heritage: preserving and enhancing the values of our built heritage for future generations. Leeuwarden, the Netherlands.

https://www.acecae.eu/fileadmin/New_Upload/_15_EU_Project /Creative_Europe/Conference_Built_Heritage/LEEUWARDEN STATEMENT_FINAL_EN-NEW.pdf. Consulted March 12, 2019.

Apple, 2014. Getting started with iBeacon. https://developer.apple.com/ibeacon/. Consulted March 14, 2019.

Bassanelli, M., Postiglione, G., 2013. Re-enacting the past. Lettera Ventidue, Siracusa.

B.E.M. Research, 2018. Rapporto sull'e-Tourism. Cresce il turismo in Italia, nonostante l'offerta digitale inadeguata. https://www.bemresearch.it/wpcontent/uploads/2018/08/bemresearch-rapporto-e-tourism2018.pdf Consulted March 14, 2019.

Boglione, M., 2012. L'Italia murata. Bunker, linee fortificate e sistemi difensivi dagli anni Trenta al secondo dopoguerra. Blu edizioni, Torino.

Buhalis, D., 2003. eTourism: information technology for strategic tourism management. Pearson, London.

Council of Europe, 2005. Framework Convention on the Value of Cultural Heritage for Society. Council of Europe Publishing, Paris.

Council of Europe, 2009. Heritage and beyond. Council of Europe Publishing, Paris.

Corbellini, G., 2016. Lo spazio dicibile. Architettura e narrativa. Lettera Ventidue, Siracusa.

D'Eramo, M., 2017. Il selfie del mondo. Indagine sull'età del turismo. Feltrinelli. Milano.

Fairclough, G., Dragićević-Šešić, M., Rogač-Mijatović, L., Auclair, E., Soini, K., 2014. The Faro Convention, a new paradigm for socially - and culturally - sustainable heritage action. Култура / Culture, 8, 9-19. 
Fernandes Vaz, R.I., Fernandes, P.O., Rocha Veiga, A.C., 2018. Interactive Technologies in Museum: How Digital Installations and Media are enhancing the Visitors' Experience. In Rodrigues, J.M.F., Ramos, C.M.Q., Cardoso, P.J.S., Henrique, C., (eds.). Handbook of Research on Technological Developments for Cultural Heritage and eTourism Application. IGI Global, Hershey. PA, USA, 30-53.

Galani, A., Maxwell, D., Mazel, A., Sharpe, K., 2011. Situating Cultural Technologies Outdoors: Designing for Mobile Interpretation of Rock Art in Rural Britain. In Trant, J., Bearman D., (eds). Museums and the Web 2011: Proceedings. Toronto: Archives \& Museum Informatics.

https://www.museumsandtheweb.com/mw2011/papers/situating _cultural_technologies_outdoors_desig. Consulted March 14, 2019.

ICOMOS, 2013. The Burra Charter. The Australia ICOMOS Charter for Places of Cultural Significance. Australia ICOMOS Incorporated International Council of Monuments and Sites, Australia.

Kaufmann, J.E., Kaufmann, H.W., 2003. Fortress Third Reich. German fortifications and defense systems in Word War II. Capo Press, Cambridge.

Kuflis, T., Lanir, J., Dim, E., Wecker, A., Corra, M., Zancanaro, M., Stock, O., 2011. Indoor Positioning: Challenges and Solution for Indoor Cultural Heritage Sites. Proceedings of the 2011 International Conference on Intelligent User Interfaces, February 13-16, 2011 Palo Alto, CA, USA. ACM, New York, 375-378.

Liuc Università Catteneo, 2015. AMAmI. Progetto di valorizzazione dei beni culturali abilitata dalla tecnologia. http://www.liuc.it/wp-

content/uploads/2016/09/libroAMAmI.pdf Consulted March $14,2019$.

Manovich, L. 2001. The Language of New Media. The MIT Press, Cambridge, Massachusetts.

Mariotti, C., Ugolini, A., Zampini, A., 2018. I bunker tedeschi a difesa della Linea Galla Placidia. Conservare un patrimonio dimenticato. Archistor, 9, 148-193.

Montemaggi, A., 2008. Clausewitz sulla linea gotica: come la superiore tattica tedesca riuscì a bloccare l'attacco dei soverchianti eserciti alleati. Angelini, Rimini, 35.

Network of European Museum Organization, 2017. Museum trends and prospect for 2018. We are museum.

https://www.ne-

mo.org/fileadmin/Dateien/public/Activities_2017-

2021/Training_Courses/2017_FR_Paris/We_Are_Museums_-

_Trends_and_prospects_for_2018-min.pdf Consulted March 14, 2019.

Osservatorio sul turismo dell'Emilia Romagna, 2019. Il turismo in Emilia-Romagna. Gennaio-dicembre 2018. Stime e proiezioni del movimento turistico nei diversi comparti dell'offerta regionale.

https://www.ucer.camcom.it/osservatori-regionali/os-

turistico/pdf18/2018-rapporto-turismo-er-gen-dic.pdf/view

Consulted March 14, 2019.
UNESCO, 2011. Recommendation on the Historic Urban Landscape. United Nations Educational, Scientific and Cultural Organization, Paris.

UNESCO, ICCROM, ICOMOS, IUNC, 2013. Managing Cultural World Heritage. UNESCO World Heritage Centre World Heritage Resource Manual, Paris.

Vavoula, G., Coleman, S., Jones, R., 2015. Museum: Beacons for interpretation. Research and Development Report. https://www.researchgate.net/publication/301199251_Leicester _Arts_Museums_Beacons_for_interpretation. Consulted March $14,2019$.

Vilirio P., 1975. Bunker Archéologie. Centre Georges Pompidou, Paris. 